\title{
MULTI-PHYSICS SIMULATION OF 6/4 SWITCHED RELUCTANCE MOTOR BY FINITE ELEMENT METHOD
}

\author{
Renata R. C. Reis ${ }^{1}$, Marcio L. M. Kimpara ${ }^{1}$, João O. P. Pinto ${ }^{1}$, Babak Fahimi ${ }^{2}$ \\ ${ }^{1}$ Federal University of Mato Grosso do Sul, Campo Grande - MS, Brazil \\ ${ }^{2}$ University of Texas at Dallas, Richardson - TX, USA \\ e-mail: renatarezendereis@gmail.com,marcio.kimpara@ufms.br
}

\begin{abstract}
The switched reluctance motor (SRM) performance can be improved by either drive control and/or machine design. However, the drive control may be more complex and expensive depending on the SRM design, whereas a favorable SRM design may result in simpler and cheaper drive control system. In order to evaluate the SRM performance before designing the control/drive system, it is important carrying out a multiphysics simulation of the machine, in such way that if electromagnetics, structural and thermal performance do not cope with the requirements for simpler control/drive system, the SRM can be redesigned until reach a feasible goal. This paper presents a comprehensive simulation analysis of a 6/4 three-phase SRM using the finite element method as evaluation approach for future use in optimization design techniques. First, the main geometrical parameters of the motor were calculated and then static and dynamic simulations were conducted to analyze the motor electromagnetic performance. Afterwards, the natural frequencies and vibration modes were found through modal analysis. Finally, the thermal analysis was accomplished to investigate the internal temperature rise due to the copper losses. The analysis has been performed in ANSYS package, providing an insightful guidance for the near optimum motor designing stage.
\end{abstract}

Keywords - Finite Elements, Modal Analysis, Power Electronics, Switched Reluctance Motor, Thermal Analysis.

\section{INTRODUCTION}

Although the knowledge behind the principle of operation governing the switched reluctance motors (SRM) dates back to the early 19th century, it has been largely studied after the power electronics enhancement, around the 1960s, when the drive research for double reluctance machine using power thyristors began [1]. Attractive characteristics of this machine, such as robustness, manufacturing low cost, wide speed range and high efficiency have made it gain notoriety in recent years. As a result, it is possible to find several applications for SRM, namely, electric transportation, washing machines, vacuum cleaners and compressors [2-4]. Thus, the growing interest and technological demand on this type of motor has encouraged researches to attempt optimize the machine design in order to mitigate its drawbacks, making it even more competitive. The SRM drawbacks lie on the torque pulsation and vibration/acoustic noise levels, deemed more severe than its counterparts. There are two main possible approaches to face these issues: the optimization of the drive control techniques or machine design itself [5].

Regarding the SRM design, there are some papers in the literature that report the geometrical calculations and the electromagnetic performance [6], however very few works address the SRM design in its entirety, i.e., considering the mechanical and thermal behavior. As an inherent characteristic due to principle of operation, a sudden change in the radial force produces a large vibration, which in turn will produce acoustic noise emitting from the stator frame. The resulting vibration and acoustic noise can be particularly severe if mechanical resonances are triggered [7]. Therefore, structural modal analysis in the design stage is an important tool preventing mechanical restrictions and useful to guide the motor structure optimization instead of choosing another pole arrangement. For instance, less vibration and torque pulsation might be achieved by SRMs with greater number of teeth, nonetheless, the power electronic converter to drive such motor is more complex and expensive due to the increasing number of arms/switches.

Likewise, temperature is critical to the service life, safety performance and overall efficiency of the SRM motor drive. Although the absence of rotor windings helps to limit the temperature rise, the stator cooper losses under rated current must be considered. Control techniques have been proposed aiming to increase the torque per current ratio, targeting to decrease losses, resulting in lower SRM operating temperatures.

Therefore, this paper presents a comprehensive analysis through a multi-physics simulation of a 6/4 SRM, so all operating aspects of the machine can be included in the machine design evaluation, and an interactive design process can be implemented. This model may be used in a near optimum design, resulting in SRMs that may require simpler control strategies. In order to do that, first a $2 \mathrm{~kW} \mathrm{SRM} \mathrm{is}$ designed, i.e., the main dimensional parameters of the motor have been computed. Afterwards, the electromagnetic, mechanical and thermal simulations were carried out to evaluate the designed motor, thus giving guidance to adjust the motor parameters towards an improved performance. 


\section{DESIGN PROCEDURE}

The main goal of this paper is to present the design procedure and multi-physics analysis of a particular SRM prototype, covering static and dynamic electromagnetic performance, besides structural and thermal behavior of the machine. The SRM design procedure comprehends the calculation of the dimensions illustrated in Figure 1. Table I presents the nomenclature for the parameters in that figure.

Before calculating SRM dimensions it is necessary to considerer some initial specifications, such as, power and desired output torque, material, rated speed and number of phases. These parameters are summarized in Table II. In this work, the magnetic steel M19 has been chosen for the laminations. This kind of material is very common in electric machines due to its cost benefit ratio. The maximum magnetic induction was considered $1.3 \mathrm{~T}$ based on empirical observations.

\section{A. Rotor and Stator Pole Arcs}

According to [8] the recommended range for the ratio between the stator and rotor pole arcs is from 0.85 to 1.2. However, one of the primary selection criteria for the stator and rotor pole arcs is the machine self-starting capacity at any position, i.e., the rotor pole arc should be slightly greater or equal to stator pole arc. Thus, one can start the calculation assuming the minimum value for the stator arcs as given by equation (1) [8]. The final values defined for stator and rotor

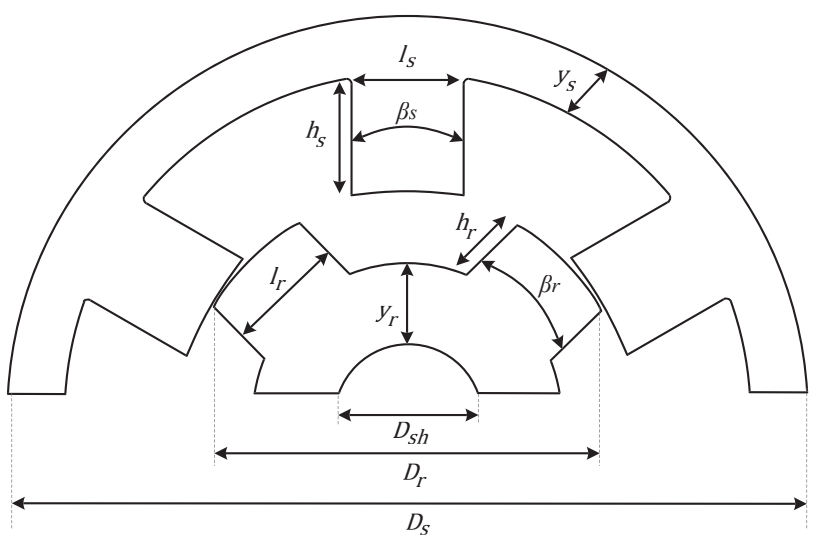

Fig. 1. SRM dimensions.

TABLE I

Design Parameters Nomenclature

\begin{tabular}{cc}
\hline Parameter & Symbol \\
\hline Stator yoke thickness & $y_{S}$ \\
\hline Rotor yoke thickness & $y_{r}$ \\
\hline Stator pole length & $l_{S}$ \\
\hline Rotor pole length & $l_{r}$ \\
\hline Stator pole arc & $\beta_{S}$ \\
\hline Rotor pole arc & $\beta_{r}$ \\
\hline Stator pole height & $h_{S}$ \\
\hline Rotor pole height & $h_{r}$ \\
\hline Shaft diameter & $D_{s h}$ \\
\hline Rotor outer diameter & $D_{r}$ \\
\hline Stator outer diameter & $D_{S}$ \\
\hline
\end{tabular}

TABLE II

Initial Specifications

\begin{tabular}{cccc}
\hline Parameter & Symbol & Value & Unit \\
\hline Output power & $P_{o}$ & 2,000 & $\mathrm{~W}$ \\
\hline Rated speed & $N_{r p m}$ & 2,000 & $\mathrm{rpm}$ \\
\hline Supply voltage & $V$ & 180 & $\mathrm{~V}$ \\
\hline $\begin{array}{c}\text { Number of rotor } \\
\text { poles }\end{array}$ & $N_{r}$ & 4 & - \\
\hline $\begin{array}{c}\text { Number of stator } \\
\text { poles }\end{array}$ & $N_{S}$ & 6 & - \\
\hline Airgap & $g$ & 0.3 & $\mathrm{~mm}$ \\
\hline Phases & $q$ & 3 & - \\
\hline Peak current & $i$ & 18 & $\mathrm{~A}$ \\
\hline $\begin{array}{c}\text { Current density } \\
\text { Maximum flux } \\
\text { density }\end{array}$ & $J_{C}$ & 5 & $\mathrm{~A} / \mathrm{mm}^{2}$ \\
\hline Material & - & 1.3 & $\mathrm{~T}$ \\
\hline
\end{tabular}

pole arcs are shown in Table $\mathrm{V}$.

$$
\beta_{s}(\min )=\frac{4 \pi}{N_{s} \cdot N_{r}}
$$

\section{B. Inner and Outer Diameter and Stack Length}

The stator internal diameter value $\left(D_{i}\right)$ is calculated from the SRM power equation given in (2) [8]:

$$
P_{m e c}=k_{e} \cdot k_{d} \cdot k_{1} \cdot k_{2} \cdot k \cdot B \cdot D_{i}^{3} \cdot A_{l} \cdot N_{r p m}
$$

where, $B$ is the magnetic induction, $A_{l}$ stands for the specific loading, which commonly varies between 25,000 and 90,000 ; $k_{e}$ is the electromechanical conversion efficiency, $k_{d}$ denotes the duty cycle, calculated according to equation (3), $k_{1}$ is a constant, defined as $\pi^{2} / 120, k$ is related to the motor's application (for non-servo application $0.25<k<0.7$ ) and $k_{2}$ depends on the operation point such as stator current value, material characteristics and geometry [8]. As in the design stage the dimensions of the machine are still uncertain the value of $k_{2}$ is within the range $0.65<k_{2}<0.75$. The values adopted in this paper for the constants in eq. (2) are summarized in Table III.

$$
k_{d}=\frac{\theta \cdot q \cdot N_{r}}{2 \pi}
$$

The external stator diameter $\left(\boldsymbol{D}_{\boldsymbol{s}}\right)$ is a fraction of the inner diameter and can be calculated according to expression (4). In this paper the ratio between inner and outer diameter is initially chosen as 0.5 .

$$
\left(D_{s} \cdot 0.4\right)<D_{i}<\left(D_{s} \cdot 0.7\right)
$$

The stack length $(\boldsymbol{L})$ is calculated as shown in equation (5), where $\boldsymbol{k}$ is the same constant defined in Table III.

$$
\boldsymbol{L}=\boldsymbol{k} \cdot \boldsymbol{D}_{\mathbf{s}}
$$

\section{Stator and Rotor Pole Width and Yoke Thickness}

The stator and rotor pole width depend on the stator internal diameter and their respective polar arcs as (6). In the case of 


\section{TABLE III}

Values of the Constants in Equation (2)

\begin{tabular}{cc}
\hline Parameter & Symbol \\
\hline$k_{d}$ & 1 \\
\hline$k_{e}$ & 0.7 \\
\hline$k_{1}$ & 0.0822467 \\
\hline$k_{2}$ & 0.72 \\
\hline$k$ & 0.7 \\
\hline$A_{l}$ & 35000 \\
\hline
\end{tabular}

the rotor, the length of the air gap $(g)$ must be accounted, yielding (7):

$$
\begin{gathered}
l_{s}=D_{i} \cdot \sin \left(\frac{\beta_{s}}{2}\right) \\
l_{r}=\left(D_{i}-2 \cdot g\right) \cdot \sin \left(\frac{\beta_{r}}{2}\right) .
\end{gathered}
$$

According to [9], the maximum flux density will be concentrated at the stator poles, thus it may be considered that the stator yoke should drive about $50 \%$ of the flux rate and must be at least half the width of the stator pole, as shown in equation eq. (8). Moreover, as noise and vibration are very known drawbacks in reluctance motors, the yoke design plays an important role for the natural frequencies of vibration [10]. Therefore, the final stator back-iron thickness shown in Table $\mathrm{V}$ has been defined after some modal simulation analysis, i.e., the final factor used in eq. (8) was 0.75 . The modal analysis will be covered in more details in section $\mathrm{V}$. The rotor yoke is defined by equation (9) following the recommendations given in [8]. The value adopted in this paper is 0.6 times the stator pole length.

$$
\begin{gathered}
\boldsymbol{l}_{\boldsymbol{s}}>y_{s} \geq 0.5 \cdot \boldsymbol{l}_{s} \\
0.5 \cdot \boldsymbol{l}_{s} \leq y_{r} \leq 0.75 \cdot \boldsymbol{l}_{s}
\end{gathered}
$$

In addition to the stator back-iron thickness increase, it has been noticed through the simulations that a $2.5 \mathrm{~mm}$ arc added to the base of the stator tooth is helpful to shift the first vibration modes to higher frequencies. Higher modal natural frequencies are generally desired since it reduces the resonance effect with lower forcing frequencies [11]. The adopted arc specification was defined after performing simulations and was based on the results presented in [12].

\section{Stator and Rotor Pole Height}

After calculating the both yokes dimensions, it is possible to calculate the height of the rotor and stator poles, according to (10) and (11). The shaft diameter $\left(D_{\text {sh }}\right)$ was defined as 25 $\mathrm{mm}$, in accordance with the IEC 72 standard.

$$
\begin{gathered}
h_{r}=\frac{D_{i}-(2 \cdot g)-D_{s h}-\left(2 \cdot y_{r}\right)}{2} \\
h_{s}=\frac{D_{s}-\left(D_{i}+2 \cdot y_{s}\right)}{2} .
\end{gathered}
$$

Both, stator and rotor poles shape, affects the distribution of the radial forces, which modifies the vibratory behavior. In cases when a low vibration range is mandatory, a special design must be considered.

\section{E. Phase Winding}

The SRM minimum number of turns per phase $\left(T_{p h}\right)$ winding is calculated from the Ampere's law, according to equation (12):

$$
T_{p h}=\frac{2 \cdot g \cdot B}{I_{p} \cdot \mu_{0}}
$$

where $\mu_{0}$ is vacuum permeability, $g$ is the air gap, $I_{p}$ is peak current value and $B / \mu_{0}$ is the magnetic field.

Therefore, the minimum number of turns per phase is calculated as 35 . However, in order to take advantage of the winding area, the number of turns per phase has been changed to 100 , i.e., 50 turns per pole. As the current density $\left(J_{c}\right)$ is 5 $\mathrm{A} / \mathrm{mm}^{2}$, the conductor cross sectional area $\left(a_{c}\right)$ indicated for the coil is calculated according to (13).

$$
a_{c}=\frac{I_{p}}{2 \cdot J_{c}} .
$$

Based on the result of eq. (13), the AWG $14\left(2.08 \mathrm{~mm}^{2}\right)$ wire has been found. According to [11] and [13], in practice, when using round conductors, the slot fill factor is selected between $35 \%$ and $60 \%$. The slot area was obtained directly from the model built in FEA software, and instead of using 50 turns per pole of AWG 14, the winding arrangement was customized to 5 parallel wires of AWG $18\left(0.82 \mathrm{~mm}^{2}\right)$, resulting in a filling factor of $49.3 \%$. The purpose of using parallel wires is to reduce the copper losses. Table IV shows the comparison between the two options. The results of the SRM design are summarized in Table V.

TABLE IV

Wire and Efficiency Commitment

\begin{tabular}{cccc}
\hline Winding & Filling factor & $\begin{array}{c}\text { Copper } \\
\text { Losses }\end{array}$ & Efficiency \\
\hline AWG 14 $\left(2.08 \mathrm{~mm}^{2}\right)$ & $25 \%$ & $172 \mathrm{~W}$ & $84 \%$ \\
\hline $5 \mathrm{xAWG} \mathrm{18}\left(5 \times 0.82 \mathrm{~mm}^{2}\right)$ & $49.3 \%$ & $87.2 \mathrm{~W}$ & $87.7 \%$ \\
\hline
\end{tabular}

TABLE V

Designed SRM Dimensions

\begin{tabular}{cccc}
\hline Parameter & Symbol & Value & Unit \\
\hline Stator yoke thickness & $y_{s}$ & 17.69 & $\mathrm{~mm}$ \\
\hline Rotor yoke thickness & $y_{r}$ & 14.16 & $\mathrm{~mm}$ \\
\hline Stator pole length & $l_{s}$ & 23.6 & $\mathrm{~mm}$ \\
\hline Rotor pole length & $l_{r}$ & 27.98 & $\mathrm{~mm}$ \\
\hline Stator pole arc & $\beta_{s}$ & 30 & degree \\
\hline Rotor pole arc & $\beta_{r}$ & 36 & degree \\
\hline Stator pole height & $h_{s}$ & 27.88 & $\mathrm{~mm}$ \\
\hline Rotor pole height & $h_{r}$ & 18.62 & $\mathrm{~mm}$ \\
\hline Shaft diameter & $D_{s h}$ & 25 & $\mathrm{~mm}$ \\
\hline Rotor outer diameter & $D_{r}$ & 91.16 & $\mathrm{~mm}$ \\
\hline Stator outer diameter & $D_{S}$ & 182.31 & $\mathrm{~mm}$ \\
\hline Stack length & $L$ & 127.62 & $\mathrm{~mm}$ \\
\hline Airgap & $g$ & 3 & $\mathrm{~mm}$ \\
\hline Turns per phase & $T_{p h}$ & 100 & - \\
\hline
\end{tabular}




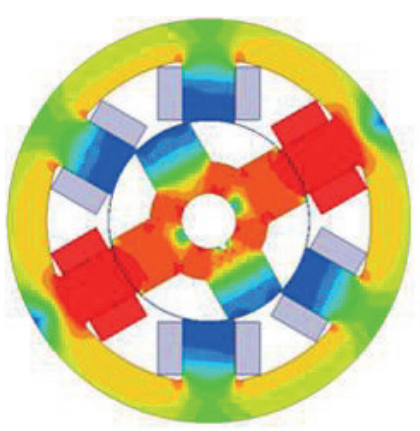

(a)

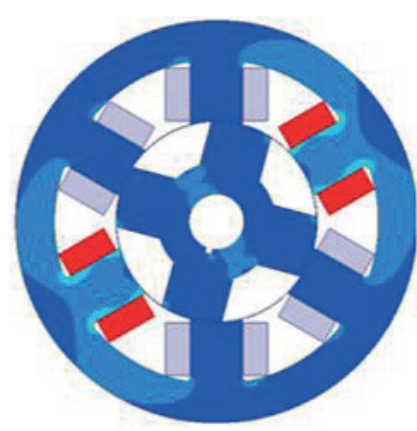

(b)

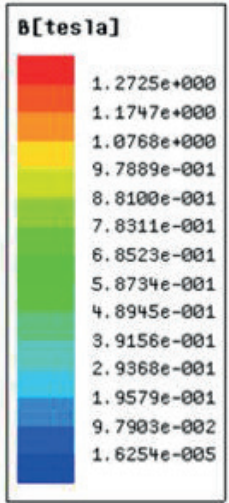

Fig. 2. Flux density: (a) aligned position. (b) misaligned position.

\section{STATIC SIMULATION: FLUX, TORQUE AND INDUCTANCE PROFILE}

The SRM designed in this paper has been simulated using Ansys ${ }^{\circledR}$ Maxwell software. The software can automatically create a mesh of elements, but it is usually not enough to achieve an accurate result. On the other hand, a very refined mesh of elements requires a very high computational effort. Thus, an alternative is to refine the mesh only in the region of interest, hence, as the torque will be evaluated, the refinement in the mesh was concentrated in the air gap. Figure 2 shows the magnetic flux density in the SRM for alignment and misalignment positions when phase $\mathrm{A}$ is excited. The magnetic material operates in saturated region because the value of flux density in the stator is close to $1.3 \mathrm{~T}$. The flux linkage profile is shown in Figure 3, where the red curve is flux for the aligned position and the blue curve represents the unaligned position. Figure 4 shows the inductance profile as a function of current and position; and Figure 5 presents the torque profile at different phase currents magnitudes. Notably, the developed torque is in accordance with the desired specification for the peak current (Table II) and the inductance profile has the dead zone, which simplifies the drive control.

\section{DYNAMIC SIMULATION: THE EFFECT OF SWITCHING ANGLE}

The static profiles analyzed in section 3 validated the magnetic design dimensions. In this section the dynamic

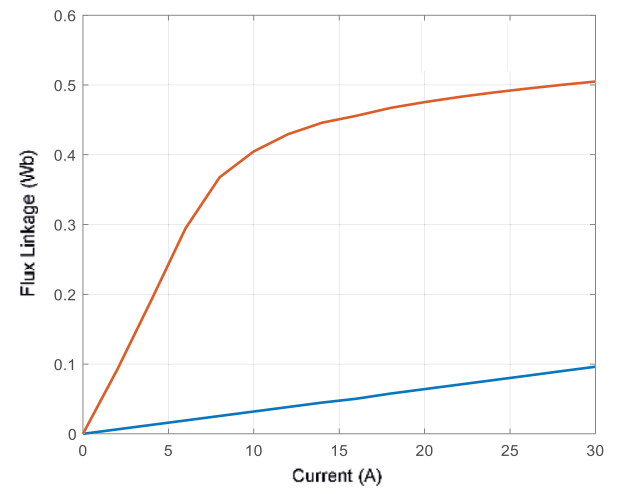

Fig. 3. Flux linkage.

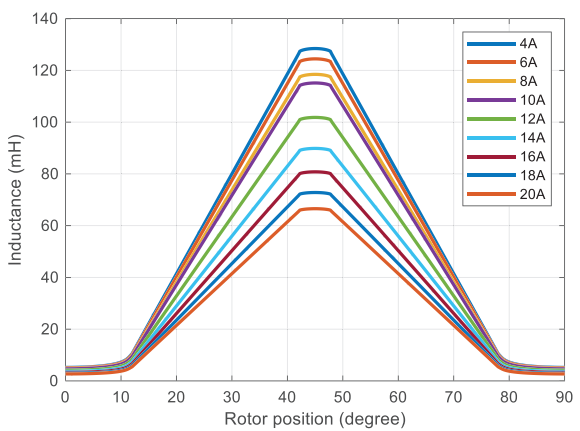

Fig. 4. Inductance profile.

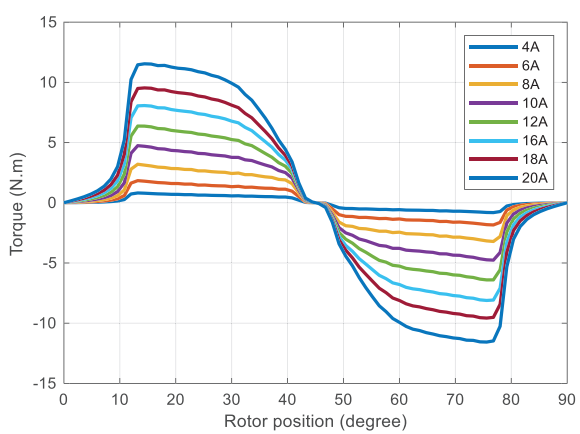

Fig. 5. Torque profile.

performance under different turn-on and turn-off angles have been investigated. The dynamic simulations were performed with ANSYS Maxwell Circuit Editor tool. The FEA model created in the Ansys Workbench was imported into Maxwell, where the phases were configured as external coils, allowing for the co-simulation between the electromagnetic model and the drive circuit. The asymmetric bridge converter circuit was built in the Simplorer module and the phase resistances were added to the circuit as well as the inductance of the coil end turn. The hysteresis current control has been used and the SRM was set in Maxwell software to operate at base speed of $2,000 \mathrm{rpm}$. Figure 6 shows the overview of the dynamic simulation scheme.

Two inputs are required to control this simulation:

1) Trigger angle: An angle of zero means that each phase will be excited in the fully misaligned position. This 
type of drive benefits the rise of the current because it has a slow growth rate.

2) Conduction angle: Generally, the current pulse has the length of the stroke angle, which for a $6 / 4$ machine is 30 degrees, however, it might vary according to the desired output characteristics of the motor or application. An important consideration is the need to control the conduction period in order to ensure that the current is reduced to zero before the inductance peak is reached, avoiding negative torque.

In order to observe the current and torque behavior of the SRM, four simulations scenarios have been analyzed, where the turn-on and conduction angles were varied for constant speed operation. The characteristics of each simulation are listed in Table VI and the results are presented in Figures 7 to 10. In each figure, (a) shows the excitation related to inductance profile, (b) shows the phase currents, (c) depicts the output torque and (d) portrays the torque versus speed curve.

TABLE VI

Simulation Characteristics

\begin{tabular}{ccccc}
\hline Parameter & Scenario 1 & Scenario 2 & Scenario 3 & Scenario 4 \\
\hline Trigger angle & $-1.25^{\circ}$ & $-1.25^{\circ}$ & $-3.75^{\circ}$ & $-1.25^{\circ}$ \\
\hline Conduction angle & $40^{\circ}$ & $37.5^{\circ}$ & $37.5^{\circ}$ & $40^{\circ}$ \\
\hline Peak current & $18 \mathrm{~A}$ & $19 \mathrm{~A}$ & $19 \mathrm{~A}$ & $19 \mathrm{~A}$ \\
\hline
\end{tabular}

In Figure 7.a (referring to simulation 1) one can note the current is applied to the phase winding almost in the complete misalignment position. In Figure 7.b the overlap technique is applied to reduce torque ripple. Figure 7.c shows that the rated torque of $9.5 \mathrm{Nm}$ is not achieved and Figure 7.d shows that the lowest output torque is close to $1.5 \mathrm{Nm}$ at $5,000 \mathrm{rpm}$.

For simulation 2 the trigger angle is the same, but the current period is shorter than in scenario 1. As result, it is possible to notice that the ripple in the output torque has been increased. Also, in attempt to reach the rated torque value, the phase current applied was change to $19 \mathrm{~A}$ instead of $18 \mathrm{~A}$, which increased the output torque in $2.4 \%$. This is confirmed in Figure 8.d at 2,000 rpm point.

As an attempt to make the current drops to zero faster, in the third simulation the trigger angle was delayed in 2.5 degrees, keeping the same conduction angle as in simulation 2. As a result, the current in Figure 9.a has a smaller inflexion in comparison with Figures 7.a and 8.a. This is also beneficial for increasing the minimum output torque as shown in Figure 9.d. The torque ripple was barely affected.

To improve the output torque, the current period was set again to $40^{\circ}$ in the fourth scenario, likewise the trigger angle was defined back as $-1.25^{\circ}$. In Figure 10.c the ripple is clearly reduced and in Figure 10.d is possible to note that at rated speed $(2,000 \mathrm{rpm})$, the torque is the rated one.

A compilation of the results is available in Table VII. One can conclude that varying some control parameters, the machine performance is affected, however, using the configuration simulated in scenario 4 , the designed motor was capable to develop the specified output torque with acceptable ripple at the desired rated speed. The efficiency was found to be around $88 \%$.
After the completion of the electromagnetic design, thermal design and structural design can be conducted. The main aim of the former is to calculate the temperature distribution in the
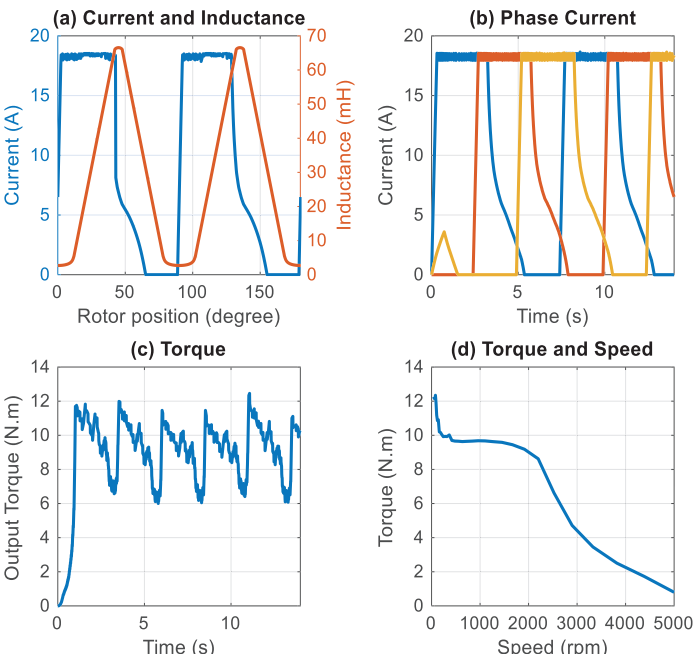

Fig. 7. Simulation results for scenario 1.
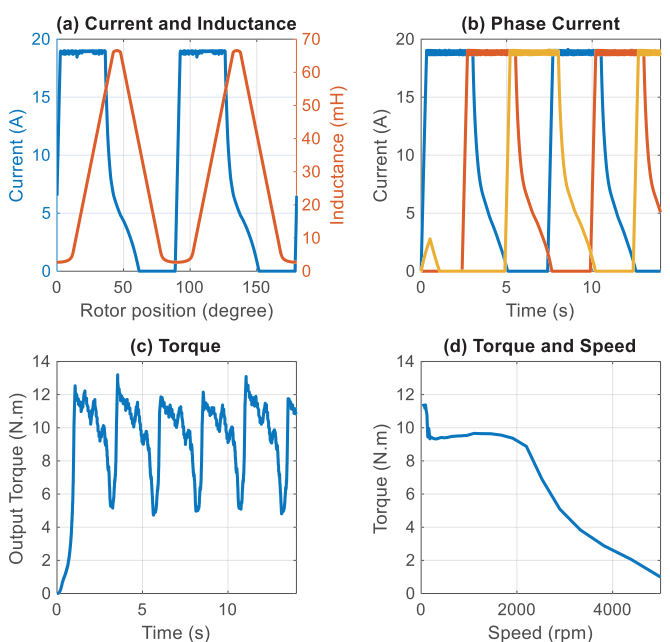

Fig. 8. Simulation results for scenario 2 .
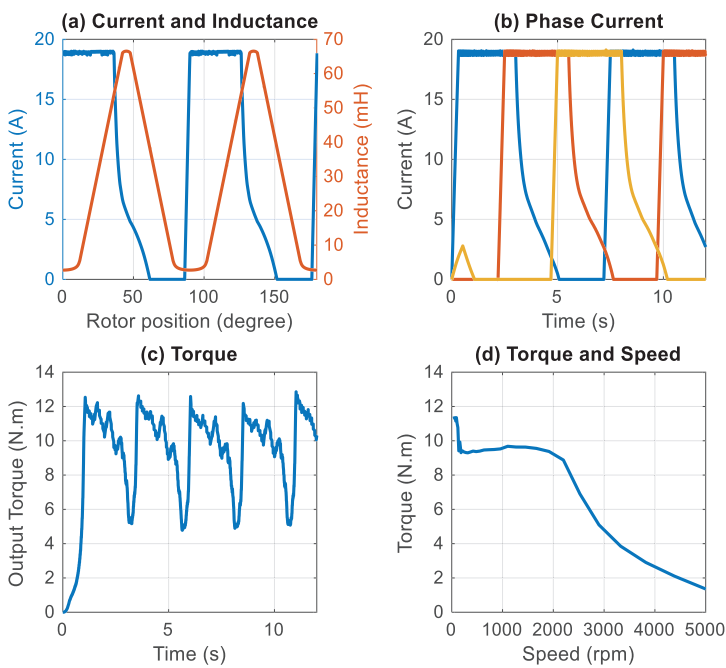

Fig. 9. Simulation results for scenario 3 . 


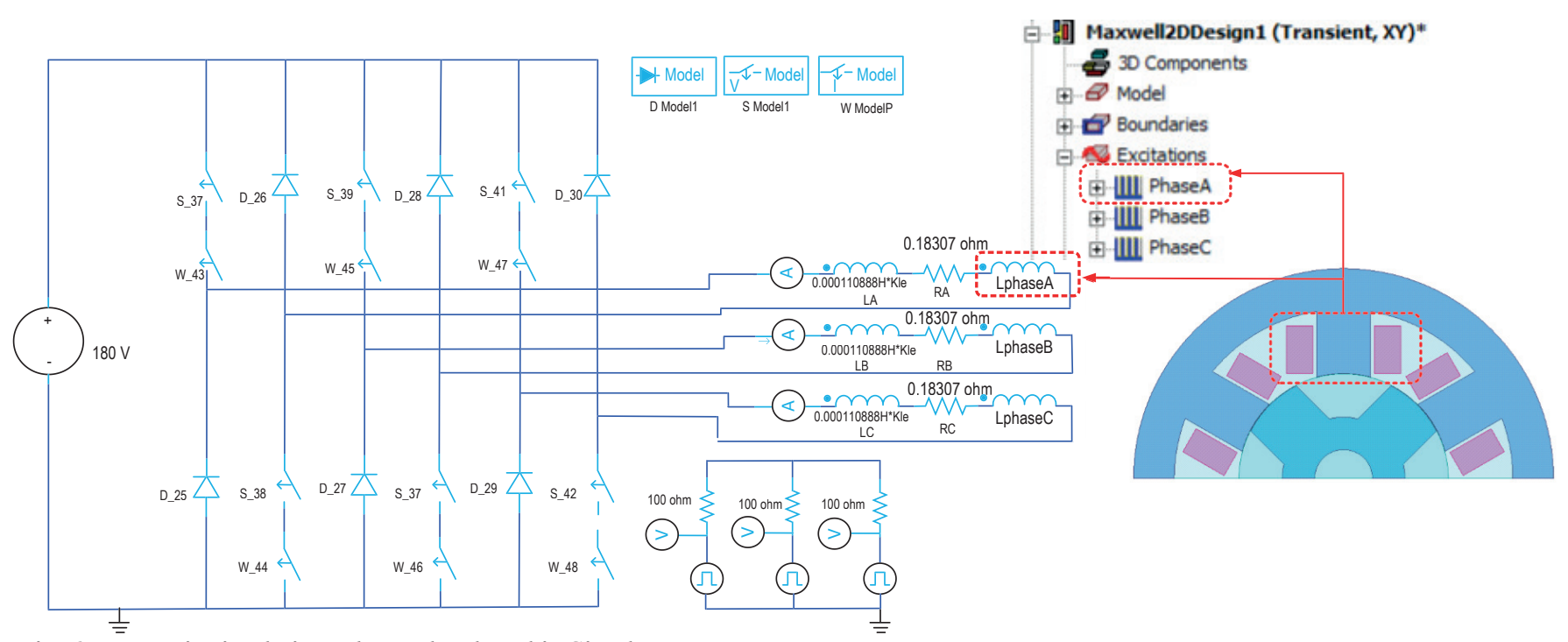

Fig. 6. Dynamic simulation scheme developed in Simplorer.

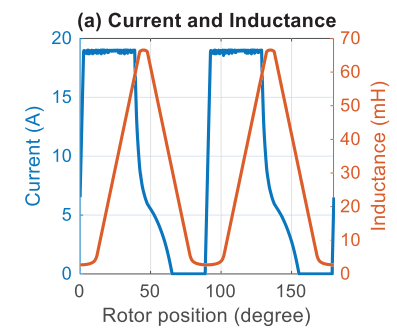

(c) Torque

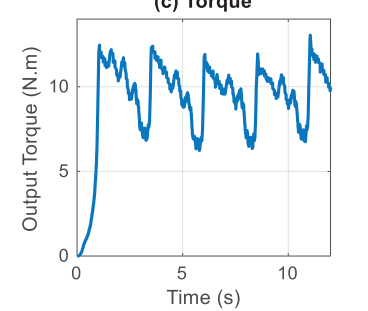

(b) Phase Current
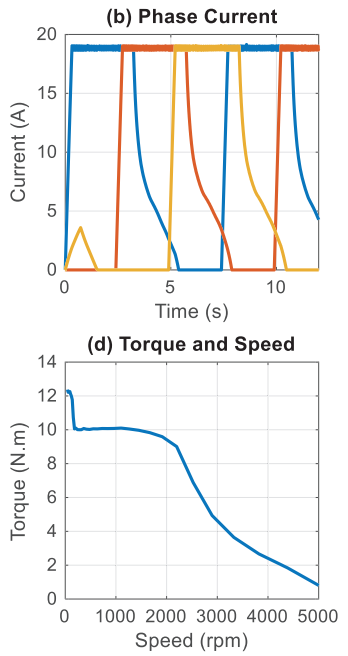

Fig. 10. Simulation results for scenario 4 .

machine based on the heat obtained from the electromagnetic analysis, meanwhile the last aims to perform the modal analysis for vibration and noise investigation, which requires special attention for some situations including high-speed application [14].

\section{MODAL ANALYSIS}

With the magnetic package defined, the structural mechanical response has been investigated through modal analysis. The modal analysis observes the natural frequencies of vibration, commonly known as resonant frequencies, defining the characteristics and shape (mode) that the motor assumes when excited in any one of these frequencies.

It is important to know the resonant frequencies in order to avoid them. Vibrations caused by improper operation at resonant frequencies can cause fatigue and also structural breakdown in the machine, besides noisy operation. Figures 11 and 12 present the results of the modal analysis performed on the stator and rotor structures using the Ansys Workbench software. The Young's modulus, Poisson's ratio and mass density of the material were defined according to the M19

TABLE VII

Simulation Results

\begin{tabular}{ccccc}
\hline & Scenario 1 & Scenario 2 & Scenario 3 & Scenario 4 \\
\hline Output torque & $9.05 \mathrm{Nm}$ & $9.7 \mathrm{Nm}$ & $9.27 \mathrm{Nm}$ & $9.47 \mathrm{Nm}$ \\
\hline Torque ripple & $65 \%$ & $70 \%$ & $69 \%$ & $52 \%$ \\
\hline Output power & $1.896 \mathrm{~kW}$ & $1.942 \mathrm{~kW}$ & $1.942 \mathrm{~kW}$ & $1.982 \mathrm{~kW}$ \\
\hline Efficiency & $87.34 \%$ & $87.92 \%$ & $87.67 \%$ & $87.74 \%$ \\
\hline
\end{tabular}

steel properties.

It is worth remembering that the deformation depends on the magnitude of the radial and tangential forces at the resonant frequencies and, even if this force is not enough to permanently damage the motor, the acoustic noise will be present. Typically, many papers only consider the stator vibration modes, however, an analysis of the rotor modes is also encouraged once the rotor is in mechanical tandem with the stator via bearings and end plates. Thus, it is possible that vibration of rotor to be transmitted to the stator (hence increasing the acoustic noise and mechanical stress) due to the cross-coupling effect [15].

In order to change the modal frequency of the motor, a designer may change motor's geometry, such as back-iron thickness. Thus, if it is expected to drive the motor at a certain switching frequency range, and if the modal analysis shows vibration modes in that range, the designer should go back and modify the machine parameters. As accomplished in the paper, a high slot filling factor also helps to improve the mechanical behavior of the motor.

\section{THERMAL ANALYSIS}

In order to avoid problems such as performance quality drop and deterioration of winding insulation, thermal management of the motor is crucial. It is known that the temperature variation inside the motor depends on the heat generated internally and on the ambient temperature.

Furthermore, thermal analysis is useful to verify the natural cooling capacity, which indicates if it is necessary to increase the volume of the machine, decreasing the power density. In this section it will be discussed the details of a $3 \mathrm{D}$ thermal 


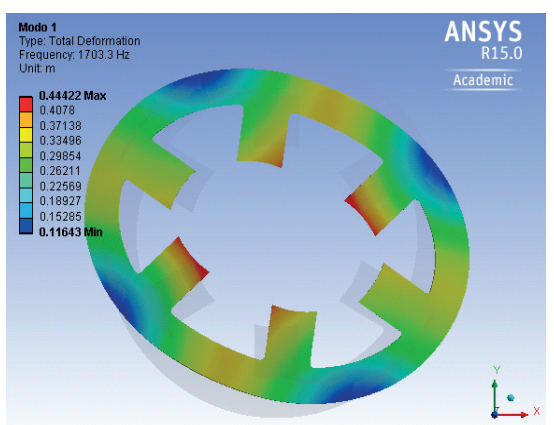

(a)

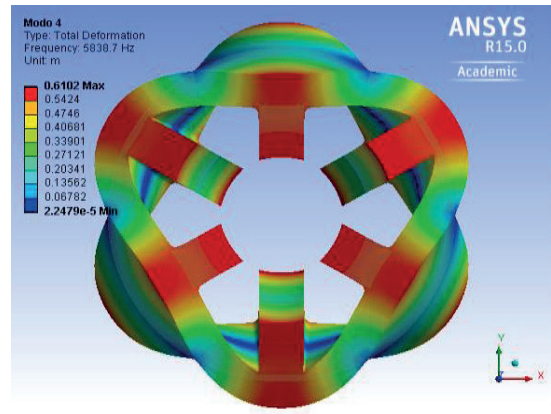

(d)

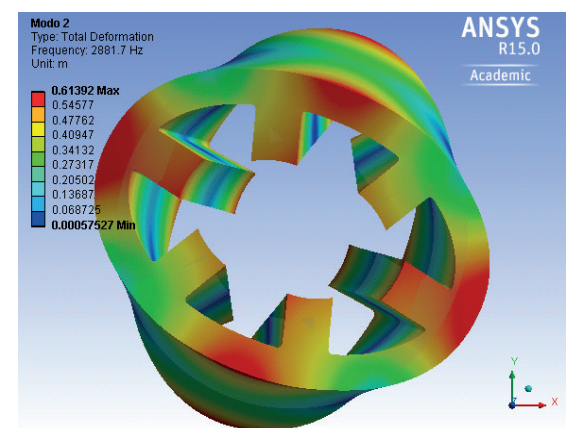

(b)

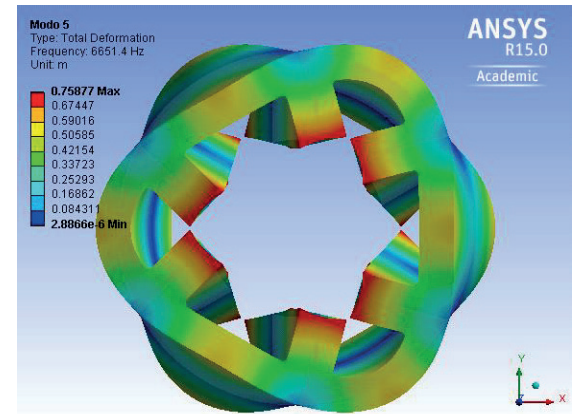

(e)

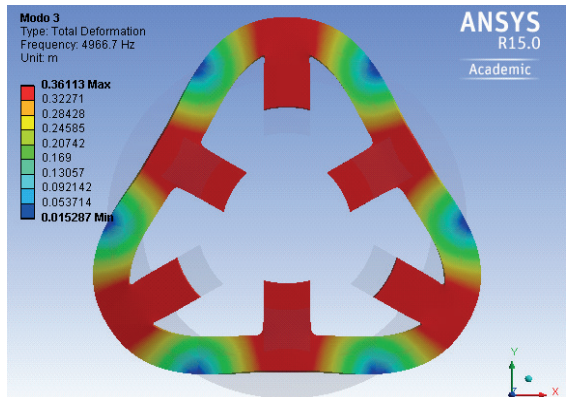

(c)

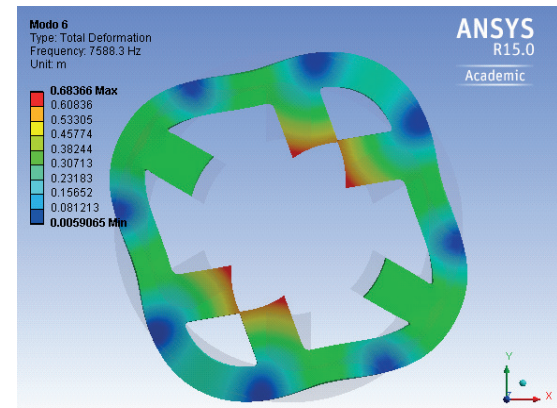

(f)

Fig. 11. Stator modal shapes. (a) 1703.3 Hz. (b) 2881.7 Hz. (c) 4966.7 Hz. (d) $5838.7 \mathrm{~Hz}$. (e) 6651.4 Hz. (f) $7588.3 \mathrm{~Hz}$.

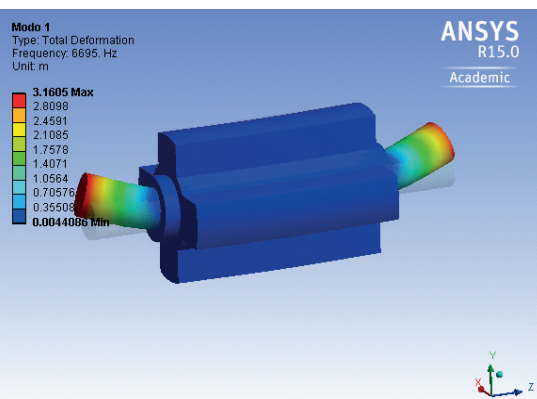

(a)

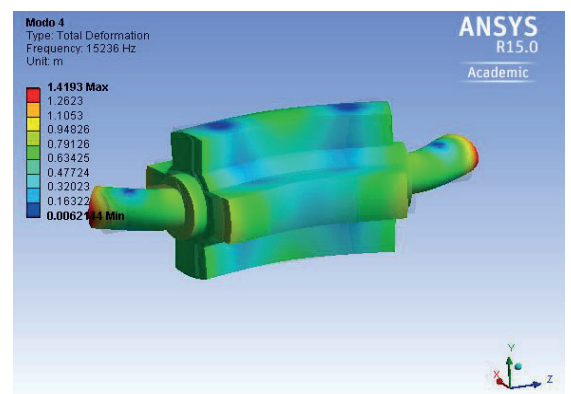

(d)

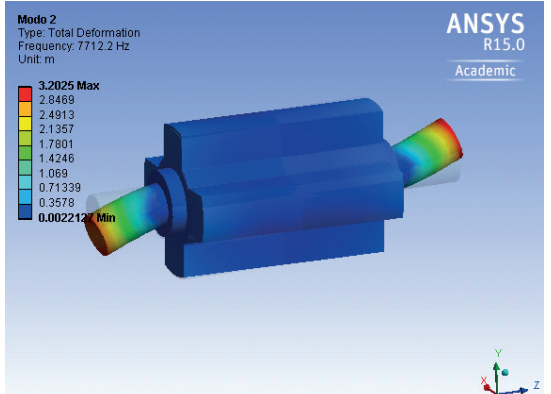

(b)

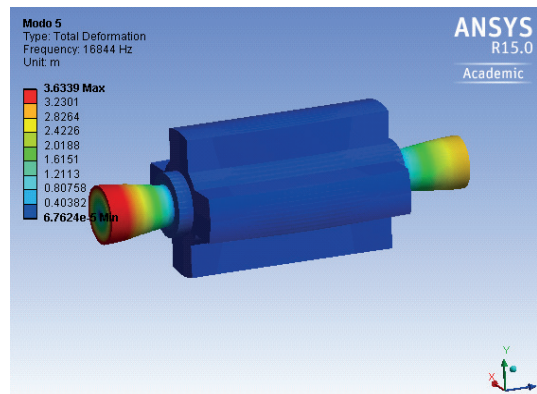

(e)

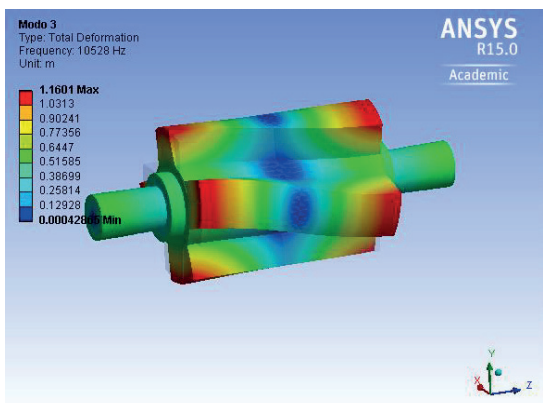

(c)

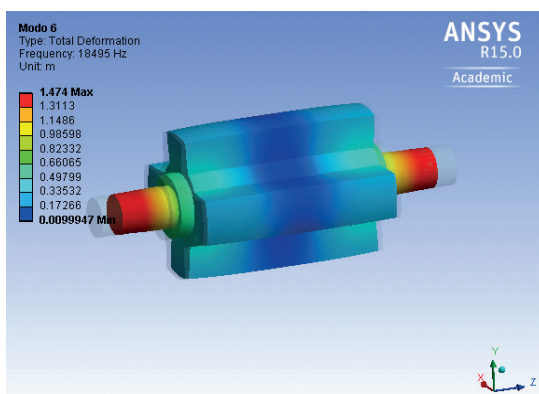

(f)

Fig. 12. Rotor modal shapes. (a) 6695 Hz. (b) 7112.2 Hz. (c) 10528 Hz. (d) 15236 Hz. (e) 16944 Hz. (f) 18495 Hz.

simulation using FEA in order to analyze the temperature rise, from the initial ambient temperature to its maximum value, as well as to analyze how this temperature is distributed by the motor structure, in the rated operation condition. According to [11], it is a rule of thumb that a $10^{\circ}$ Celsius increase in temperature will reduce the service life of the windings by half.
Generally, the heat sources for rotating electric machines are of two distinct natures: electric (Joule losses in the windings and losses in the iron) and mechanical (friction and ventilation). This work is targeted at the thermal analysis considering the joule losses as heat source. As simulation 4 presented the best results, it was taken as the basis for the thermal simulation, using Transient Thermal Analysis. The 
copper losses result estimated from Ansys is detailed in Table VIII. The sources of copper losses are the stator coils, which are configured as sources of internal heat $\left(\mathrm{W} / \mathrm{m}^{3}\right)$ and calculated by expression (14).

$$
H_{g}=\frac{\text { Copper Losses }(W)}{\text { Coil Volume }\left(m^{3}\right)} .
$$

TABLE VIII

\begin{tabular}{c} 
Copper Losses From Simulation 4 \\
\cline { 2 - 2 } \\
\begin{tabular}{cc} 
Speed & $2,000 \mathrm{rpm}$ \\
\hline Copper losses & $87.24 \mathrm{~W}$ \\
\hline
\end{tabular}
\end{tabular}

After obtaining the heat sources, it is necessary to define the boundary conditions, for example, to determine the coefficients of heat transfer between the bodies and the air, in addition to the initial temperature. The motor's outer surface and the surface of the stator lamination has a natural convection heat transfer and its ambient temperature is considered around 22 degrees Celsius. The value of the heat transfer coefficient for natural convection is calculated by the empirical equation (15).

$$
h_{n c}=10.45-v+10 \sqrt{v}\left(W / m^{2} K\right) .
$$

Due to the movement of the rotor, the internal surface of the motor is immersed in a forced convection environment. The exact calculation of the heat transfer coefficient for forced convection is complex due to the need to predict the initial temperature inside the machine [16]. The air flow created by the movement of the rotor can be considered turbulent, which means that its velocity is considered the same as that of the rotor. In this case, the rotor will maintain the lowest temperature because the air layer of the air gap isolates it from the thermal sources in the stator, thus reinforcing the theory that the rotor position does not interfere with the temperature distribution [17]. The results of [18] show that the value of 30 $\mathrm{W} / \mathrm{m}^{2} \mathrm{~K}$ for the convection heat transfer coefficient is quite reasonable for the speed of rotation of 2,000 rpm and shows good correlation with experimental results, being this value applied throughout the internal surface of the motor. Figure 13 presents the details of the thermal simulation preparation. As one can note, the rotor has been suppressed from this analysis due the reasons described above. Also, a forced convection heat transfer $\left(30 \mathrm{~W} / \mathrm{m}^{2} \mathrm{~K}\right)$ has been set internally (air flow created by motion) and a natural convection heat transfer (10 $\mathrm{W} / \mathrm{m}^{2} \mathrm{~K}$ ) was applied between the heat sink and the ambient. Figure 14 shows the contacts between the bodies, which must also be defined in the pre-simulation process.

Because of the Joule losses, the hottest point in the motor are the coils. In this way, the first simulation was accomplished to know the maximum coil temperature when the losses indicated in Table VIII are generated internally. As a result, Figure 15 depicts the maximum temperature curve (red) and the minimum temperature point (blue) after approximately two hours of intermittent operation. The coil temperature converges to approximately 45 degree Celsius. A second simulation was performed aiming to investigate how the temperature is distributed through the machine body.
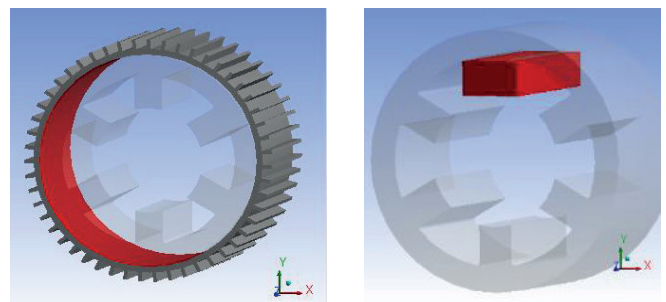

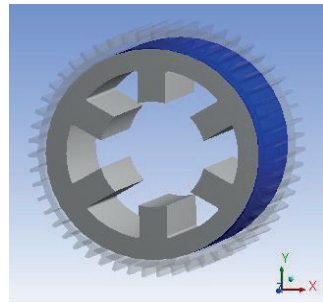

(a)

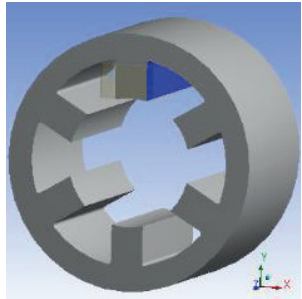

(b)
Fig. 14. Bodies contacts. (a) Contact between the heat sink and the stator. (b) Contact between the coil and rotor tooth.

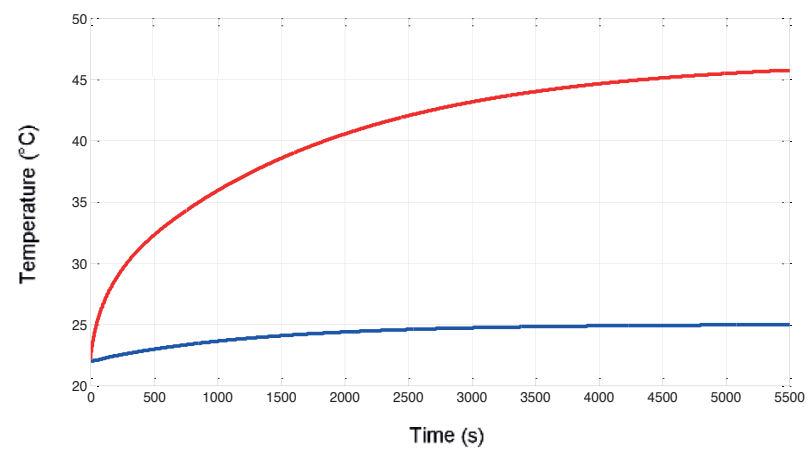

Fig. 15. Temperature convergence.

The maximum temperature of 45 degree Celsius has been applied to the coils as shown in the pre-simulation process illustrated in Figure 16. The post-processing result for the heat distribution is shown in Figure 17. It is observed that the temperature is distributed from the stator teeth to the rest of the machine structure. In the frame is possible to notice the appearance of hot spots in the same direction as the stator teeth, which is in agreement with images obtained with thermal cameras in similar motor designs, for example. Therefore, the results suggest that under nominal conditions, the SRM can operate safely, since the maximum temperature is below the value established by the IEC 60085 standard for winding insulation classes of electric motors.

\section{NEAR OPTIMUM SRM DESIGNING CONSIDERATIONS}

As stated in [14], the electrical machines design process becomes more complex as more engineering domains and constraints are involved, such as electromagnetics, structural mechanics and heat transfer. Thus, the design process includes two main stages: design and optimization. The designing procedure of the electric motor should take into account, besides the properly theory equations, the physical characteristics of the materials. In the first approach, the preliminary design is based on geometry equations. The next step is to create the designed geometry in a simulation 


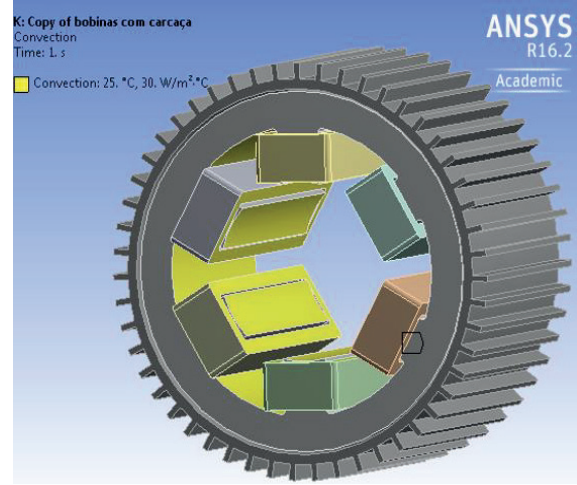

(a)

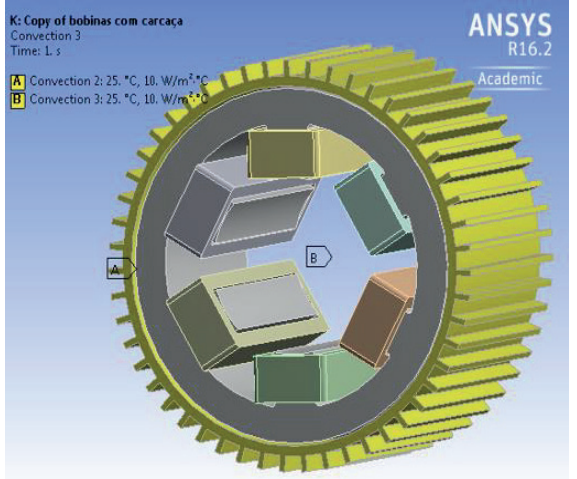

(b)

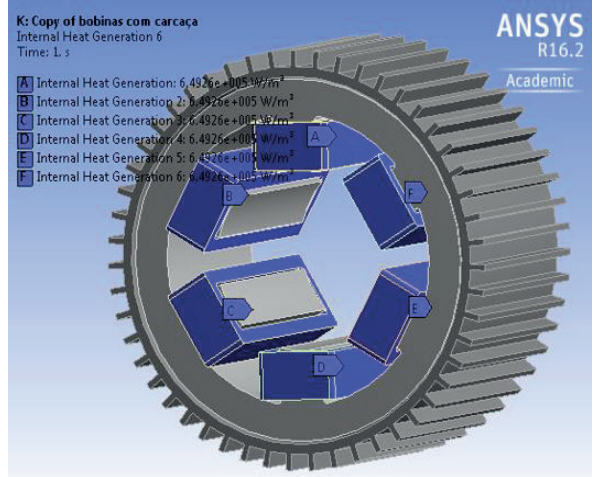

(c)

Fig. 13. Surfaces: (a) Forced convection. (b) Natural convection. (c) Heat sources.

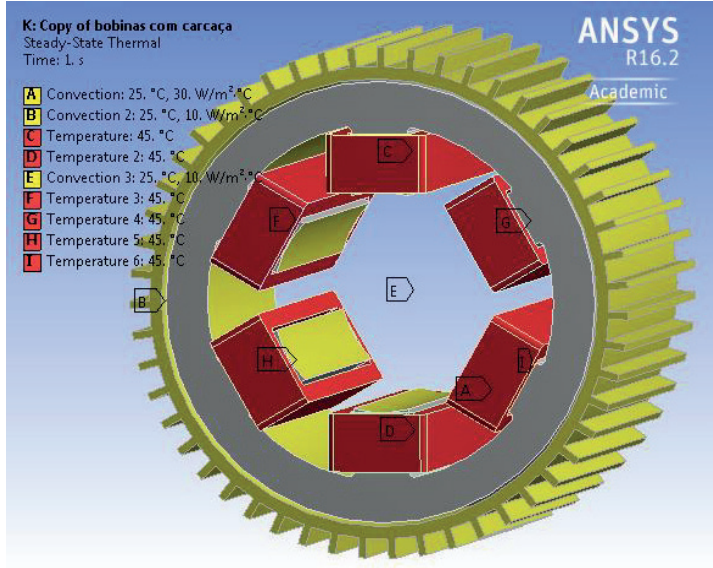

Fig. 16. Coils as heat generator.

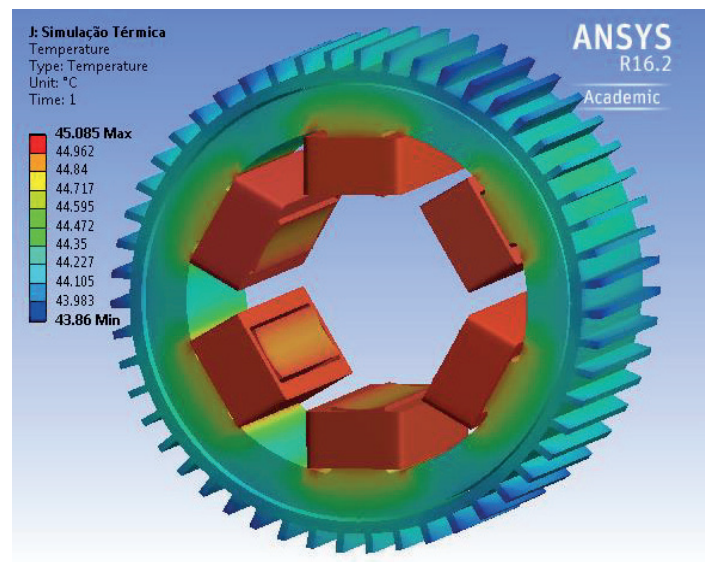

Fig. 17. Heat distribution.

environment to analyze the output response of the model, usually a FEM-based model. The next step is to analyze the model in three main aspects: electromagnetic, thermal and structural. The main aim of the design stage is to find a feasible scheme through the investigation of different materials and dimensions, multi-disciplinary analysis and design experience. The analysis of this stage will provide information including motor parameter calculation and performance evaluation for the development of optimization model that will be used in the next stage. [14].

The majority of geometry equations are an initial trial but

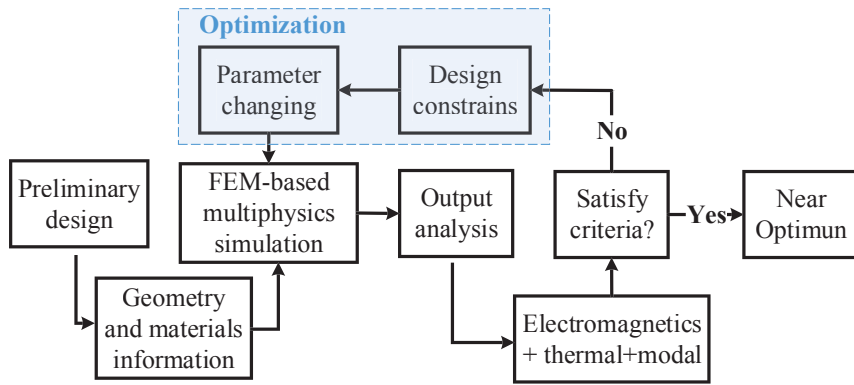

Fig. 18. Optimum design process diagram.

do not guarantee the performance well aligned with the requirements, hence some adjustments may be applied to the very first model, leading to a near optimum design. However, some specific parameter changing can be more effective for a particular response, and if there are a large amount of design constrains, or a multi objective optimization is being applied, an optimization algorithm is mandatory [19]. The main target of optimization stage is to improve the performance of the motor proposed in the design stage. The diagram of the optimization and designing process is shown in Figure 18.

Therefore, an optimized model involves selecting objectives, constrains and the algorithm (classic or modern intelligent algorithms). Some parameters to be considered in the optimization stage are discussed.

\section{A. Design Considerations For Reduction of Acoustic Noise}

Since noise is caused in SRM by the abrupt change in the current and radial force, high magnetic flux density in the airgap should be avoided. The combination in the number of rotor and stator poles plays a very important role in noise reduction, thus multiplicity superior than one is more appropriate. In addition, since the noise is a product of high levels of vibration, it is important to guarantee high mechanical stiffness by making stator and rotor poles wide, with no long height, as well as avoiding thin yoke thickness. For the same reason, it is preferable a large diameter for the rotor shaft. On the other hand, all the above-mentioned parameters should be defined observing restrictions of the power density.

As mentioned in item section II.C, the addition of an arc to the base of the stator tooth is beneficial to shift the first vibration modes to higher frequencies. 
Concerning the SRM drive, it is possible to computationally build an optimal profile for the excitation current, in which an active cancelation of the vibration is implemented [20]. Another approach is the increasing of the switching frequency, which is applicable in low-medium speed range, due to the rise of the back-EMF in high operation speeds [21].

\section{B. Design Consideration For Reduction of Torque Ripple}

The average torque generation in SRMs is highly dependent of the geometry on air-gap as well as the switching pattern of the SRM drive, i.e. the turn-on and turn-off angles. As reported in section $I V$, the turn-on and conduction angles have a very notable influence on the output response of the motor, and the search for an optimum combination of both is an optimization problem.

Besides, hard chopping and soft chopping can influence the torque profile in SRM, as well as the switching frequency, that should be high to minimize the torque ripple and, if possible, above the human audible range. The overlap between conducting phases is also encouraged. Likewise, current profiling is a possibility, whereas a symmetric profile is the most desirable [22].

Changing the geometry of the stator and rotor poles is a very powerful option to optimize the SRM torque profile. The choice of the rotor and stator pole arcs plays the first optimization problem in the design process. The torque ripple is sensitive to the rotor and stator pole arcs, and to the diameter of the rotor. Furthermore, it is also possible to skew the rotor or stator poles, to guarantee a more symmetric distribution of the torque profile [23].

\section{CONCLUSIONS}

The electric motors requirements are getting stricter. Combined with a suitable electromagnetic performance, mechanical vibration and thermal signature are also important metrics to assess the motor design. In this work the design of a 6/4 three phase switched reluctance motor of $2 \mathrm{~kW}$ and 2,000 rpm has been presented. Subsequently, the designed motor was modeled in the ANSYS finite element software to accomplish a complete multi-physics finite element analysis including the electromagnetic, structural stress and temperature rise and distribution. Magnetic characteristics such as static torque and inductance profile were evaluated and observed to be in agreement with the calculated values in the design stage. The characteristics of torque ripple, output power and efficiency were verified through dynamic simulations, where different drive configurations have been explored.

Simulation results showed an output power of $1,981.7 \mathrm{~W}$, average torque of 9.46 N.m and $87.74 \%$ efficiency, which are very similar to the desired specifications. The modal analysis was also studied and after some adjustments, the calculated structure presents resonance frequencies in the same range of similar commercial SRMs. Finally, a thermal analysis was performed where it was observed that the maximum winding temperature due to ohmic losses is 45 degrees Celsius and the stator blades reach $42^{\circ}$ degree Celsius.
Therefore, the multi-physics simulation results demonstrate that the proposed design can be considered satisfactory, as it meets the electrical, mechanical and thermal requirements. Furthermore, the presented multi-physics simulation of a $6 / 4$ SRM helped to have a general idea of the motor performance, contributing to achieve a good performance of SRM with a simpler and cheaper drive control system. If the SRM is properly designed, then a simple drive control system may increase the motor drive performance, for instance, a $6 / 4$ SRM, properly designed, may have a performance similar to an 8/6 SRM, with a simpler and cheaper converter and controller. Based on this multi-physics simulation, performance indexes can be proposed for the creation of a cost function that can be used in near optimum SRM design processes. It can be included, as future work, the manufacturing and experimental validation of the proposed SRM design methodology, as well the near optimum design algorithm, based on differential evolution.

\section{REFERENCES}

[1] T. J. E. Miller, Brushless Permanent Magnet and Reluctance Motor Drives. Oxford University Press, Oxford, 1989.

[2] C. J. Bateman, B. C. Mecrow, A. C. Clothier, P. P. Acarnley, N. D. Tuftnell, "Sensorless Operation of an Ultra-High-Speed Switched Reluctance Machine", IEEE Transactions on Industry Applications, vol. 46, n. 6, pp. 2329-2337, Nov./Dec. 2010.

[3] T. Raminosoa, B. Blunier, D. Fodorean, A. Miraoui, "Design and Optimization of a Switched Reluctance Motor Driving a Compressor for a PEM Fuel-Cell System for Automotive Applications", IEEE Transactions on Industrial Electronics, vol. 57, n. 9, pp. 2988-2997, Sept. 2010.

[4] J. Zhu, K. W. E. Cheng, X. Xue, Y. Zou, "Design of a New Enhanced Torque In-Wheel Switched Reluctance Motor with Divided Teeth for Electric Vehicles", IEEE Transactions on Magnetics, vol. 53, n. 11, May 2017.

[5] L. O. A. P. Henriques, L. G. B. Rolim, W. I. Suemitsu, P. J. C. Branco, "Uma revisão das estratégias de redução de ondulações de conjugado no motor de relutância chaveado", Eletrônica de Potência SOBRAEP, vol. 8, n. 1, pp. 16-24, June 2003.

[6] A. Arif, A. Guettaf, A. C. Megherbi, "Electromagnetic modeling and control of switched reluctance motor using finite elements", Springer Journal Frontiers in Energy, vol. 8, pp. 355-363, 2014.

[7] C. G.C. Neves, R. Carlson, N. Sadowski, J. P. A. Bastos, N. S. Soeiro, S. N. Y. Gerges, "Vibrational Behavior of Switched Reluctance Motors by Simulation and Experimental Procedures", IEEE Transactions on Magnetics, vol. 34, n. 05, Sep 1998.

[8] R. Krishnan, Switched Reluctance Motor Drives: Modeling, Simulation, Analysis, Design, and Applications, CRC press, 2001.

[9] P. Vijayraghanvan, Design of Switched Reluctance Motors and Development of a Universal Controller for Switched Reluctance and Permanent Magnet Brushless 
DC Motor Drives. Doctoral Thesis, Virginia Polytechnic Institute and State University, 2001.

[10] E. S. Serafim, Influência dos Parâmetros Geométricos no Comportamento Vibracional e Acústico de um Motor de Relutância Chaveado. Tese de Doutorado, Universidade Federal de Santa Catarina, 2002.

[11] B. Bilgin, J. W. Jiang, A. Emadi, Switched Reluctance Motor Drives - Fundamentals to Applications. CRC Press, Boca Raton, 2018.

[12] E. Kotaro, I. Miki, "Design of Stator and Rotor for Noise Reduction of SRM", in Proc. of International Conference on Electrical Machines and Systems (ICEMS), Hangzhou, Oct. 2014.

[13] C. Laudensack, Q. Yu, D. Gerling, "Loss Reduction of a Canned Switched Reluctance Machine", in Proc. of International Conference on Electrical Machines (ICEM), Marseille, Sept. 2012.

[14] G. Lei, J. Zhu, Y. Guo, C. Liu, B. Ma, "A Review of Design Optimization Methods for Electrical Machines", Energies, MDPI, vol. 10, n. 12, pp. 1-31, 2017.

[15] M. L. M. Kimpara, S. Wang, R. R. C. Reis, J. O. P. Pinto, M. Moallen, B. Fahimi, "On the cross coupling effects in structural response of switched reluctance motor drives", IEEE Transactions on Energy Conversion, vol. 34, n. 2, pp. 620-630, June, 2019.

[16] J. Faiz, B. Ganji, C. E. Carstensen, R. W. de Donker, "Loss prediction in switched reluctance motors using finite element method", European Transactions on Energy Systems, vol. 19, n. 5, pp. 731-748, July, 2009.

[17] K. N. Srinivas, R. Arumugam, "Analysis and characterization of switched reluctance motors: Part II. Flow, thermal and vibration analysis", IEEE Transactions on Magnetics, vol. 41, n. 4, pp. 1321-1332, April 2005.

[18] S. Inamura, T. Sakai, K. Sawa, "A temperature rise analysis of switched reluctance motor due to core and copper loss by FEM", IEEE Transactions on Magnetics, vol. 39, n. 3, pp. 1554-1557, May 2003.

[19] S. Zhang, S. Li, R. G. Harley and T. G. Habetler, “A multi-objective analytical design approach of switched reluctance machines with integrated active current profile optimization", 2017 IEEE International Electric Machines and Drives Conference (IEMDC), pp. 1-6 Miami, FL, 2017.

[20] M. L. M. Kimpara et al., "Active Cancellation of Vibration in Switched Reluctance Motor Using Mechanical Impulse Response Method", IEEE Transactions on Energy Conversion, vol. 34, n. 3, pp. 1358-1368, Sept. 2019.

[21] C. Lin and B. Fahimi, "Design considerations for reduction of acoustic noise in switched reluctance drives", 2014, IEEE Energy Conversion Congress and Exposition (ECCE), pp. 1408-1413, Pittsburgh, PA, 2014.

[22] T. J. E. Miller, “Optimal design of switched reluctance motors", IEEE Transactions on Industrial Electronics, vol. 49, n. 1, pp. 15-27, Feb. 2002.

[23] C. Gan, J. Wu, M. Shen, S. Yang, Y. Hu and W. Cao, "Investigation of Skewing Effects on the Vibration Reduction of Three-Phase Switched Reluctance
Motors", in IEEE Transactions on Magnetics, vol. 51, n. 9, pp. 1-9, Sept. 2015.

\section{BIOGRAPHIES}

Renata Reis, born in 08/20/1993 in Campo Grande, Brazil, is an electrical engineer (2019), with the Federal University of Mato Grosso do Sul. She is currently a master student of electrical engineering at the Federal University of Mato Grosso do Sul, Campo Grande, Brazil. Her areas of interests include, power electronics, electric machines design and drives.

Marcio Kimpara, born in 05/07/1986 in Jales, Brazil, is an electrical engineer (2009) and master (2012) with the Federal University of Mato Grosso do Sul, and doctor in Electrical Engineering (2018) with the Federal University of Itajubá. He is currently a professor at the Federal University of Mato Grosso do Sul. His areas of interests are: power electronics, control systems, renewable energy, electric machines and drives.

João Pinto, was born in Valparaiso, Brazil. He received the B.S. degree in electrical engineering from Sao Paulo State University, Ilha Solteira, Brazil, the M.S. degree in electrical engineering from the Federal University of Uberlandia, Uberlandia, Brazil, and the Ph.D. degree in electrical engineering from the University of Tennessee, Knoxville, TN, USA, in 1990, 1993, and 2001, respectively. He is currently a Faculty Member in the Federal University of Mato Grosso do Sul, Campo Grande, Brazil. His research interests include signal processing, neural networks, fuzzy logic, genetic algorithm, and wavelet applications to power electronics, pulse width modulation techniques, drives, and electric machine control.

Babak Fahimi, received the B.S. and M.S. degrees in electrical engineering with the highest distinction from the University of Tehran, Tehran, Iran, in 1991 and 1993, respectively, and the Ph.D. degree in electrical engineering from Texas A\&M University, College Station, TX, USA, in 1999. He has been the recipient of DAAD scholarship from 1993 to 1995, the IEEE R.M. Bass Power Electronics Young Investigator Award (2003), SAE Ralph Teetor Educational award (2008), Fulbright scholarship in 2010, and the IEEE Cyril Veinott electromechanical energy conversion award in 2015. He has authored/coauthored 300 (85 Journal and 215 peer reviewed conference papers) scientific articles, 15 book chapters, and several technical reports in the general area of adjustable speed motor drives and power electronics. He holds 18 US patents and has 6 more pending. He is a contribution to the modeling and analysis of adjustable speed ac motor drives. 